\title{
Aplicación de la teledetección para el análisis de vías de acceso hacia asentamientos informales
}

\section{Application of remote sensing for the analysis of access roads to informal settlements}

\author{
Brillitt Manzané , Ilka Fiol $^{l}$, Nathalye Camaño ${ }^{l}$, Nadja Vega ${ }^{l}$, Jorge Quijada-Alarcón ${ }^{l *}$. \\ ${ }^{1}$ Licenciatura en Ingeniería Geomática- Facultad de la Ingeniería Civil- Universidad Tecnológica de Panamá, Facultad de \\ Ingeniería Civil, Universidad Tecnológica de Panamá
}

\begin{abstract}
Resumen El objetivo de este estudio es analizar las vías de acceso hacia los asentamientos informales de Kuna Nega, Altos de la Torre y Paso Blanco, ubicados en la Ciudad de Panamá, República de Panamá. Para ello, se utilizaron imágenes satelitales que permitieron observar y analizar estos asentamientos a través de la teledetección y los sistemas de información geográfica (SIG). Con este estudio se logra caracterizar las vías de acceso hacia asentamientos informales, siendo esto una herramienta de toma de decisión para mejorar la calidad de vida de quienes habitan estas zonas.
\end{abstract}

Palabras clave Asentamientos informales, teledetección, vías de Acceso.

\begin{abstract}
The objective of this study is to analyze the access roads to the informal settlements of Kuna Nega, Altos de la Torre and Paso Blanco, located in Panama City, Republic of Panama. For this, satellite images were used that allowed observing and analyzing these settlements through remote sensing and geographic information systems (GIS). With this study it is possible to characterize the access roads to informal settlements, this being a decision-making tool to improve the quality of life of those who inhabit these areas.
\end{abstract}

Keywords Informal settlements, remote sensing, access roads.

* Corresponding authors: Jorge.quijada@utp.ac.pa

\section{Introducción}

Una carretera, camino o calle de carácter urbano y/o rural son, en términos generales, vías de acceso, y pertenecen por lo tanto al dominio público cualquiera sea su estado o condición estructural, y son administradas por el Estado [1].

El presente estudio busca, a través de la teledetección, obtener datos acerca de la superficie terrestre, sin entrar en contacto con ella, lo que permite detectar y grabar la energía emitida o reflejada por medio de sensores de radiación infrarroja insertados dentro del dispositivo y que es procesada y analizada para que esta se pueda aplicar sobre las vías de acceso hacia los distintos asentamientos informales [2]. De esta manera se pueden analizar las características de estos asentamientos informales, tales como, ubicación, las condiciones en la que se encuentran y, una posible ruta de acceso para identificar infraestructuras; calles, escuelas, atención médica, como también otras comodidades más cercanas al sitio de estudio. Mediante la teledetección se va a delimitar, detectar y clasificar los casos expuestos y así poder darles una posible solución.
Los asentamientos informales se destacan por ser una comunidad fuera de las normas establecidas por las autoridades encargadas del ordenamiento territorial. El ordenamiento territorial es entendido como un instrumento técnico, normativo, político y administrativo para la gestión del territorio, mediante el cual se planifique y se regularicen los asentamientos informales [3].

En Panamá, los asentamientos informales están conformados en su mayoría por personas que ocupan viviendas autoconstruidas bajo condiciones deficientes de habitabilidad. Estos se forman por invasiones espontáneas de terrenos, públicos o privados sin reconocimiento legal alguno, y están localizados regularmente en los límites de ciertas zonas urbanas, o en terrenos con elevados riesgos tales como laderas de altas pendientes, terrenos poco estables, zonas inundables en las márgenes de ríos y quebradas [4].

La población que genera estos asentamientos se compone actualmente, de individuos de clase media y baja, que por lo general carecen de solvencia económica y de una debida formación educativa. Por lo tanto, es primordial promover el 
manejo adecuado de las tierras, mejorar la calidad de vida y/o minimizar los riesgos de pérdidas de vidas por falta de movilidad e insalubridad; en este sentido, la movilidad urbana es el desplazamiento entre un punto y otro de la ciudad [5], y en un gran número de casos estos asentamientos informales no presentan una apropiada movilidad al estar alejados de vías de acceso adecuadas.

Aspectos como la inmovilidad, insalubridad y sedimentación en ciertas zonas no habitables han sido parte de los retos a enfrentar desde el principio de la construcción urbanística y desarrollo de Panamá. Durante la unión a Colombia y con la adquisición de tierras por parte del Ferrocarril, lograron urbanizar esas áreas, cuya construcción le da un nuevo auge, que impulsa la repoblación y el crecimiento urbano. Luego, a raíz de la separación de Panamá de Colombia, y el inicio de la construcción del Canal interoceánico, se produce una nueva ramificación en el crecimiento urbano de la ciudad de Panamá [6].

A costa de estos cambios se generaron tres puntos de importancia dentro de ese desarrollo [6]:

- La aparición de un nuevo modelo de crecimiento urbano en la ciudad de Panamá, en el área recién delimitada por la Zona del Canal.

- La presión por ampliar la capacidad de la ciudad de Panamá para acomodar la población migrante que había llegado para la construcción del Canal de Panamá y, la urgencia por ocupar nuevas tierras para permitir este nuevo crecimiento.

- El cambio más radical en la estructura y funcionamiento de la ciudad, corresponde tal vez, a la construcción de los sistemas de alcantarillado, agua potable y mejoras de calles.

Este mecanismo de reproducción del crecimiento urbano continúa fragmentando la ciudad hacia las afueras. Ante la ausencia de una política que abordase el tema de la provisión de vivienda a las clases más bajas, se inicia el proceso de 'toma de tierras' por el cual aparecen los primeros asentamientos informales en los barrios que hoy comprenden Panamá La Vieja, Puente del Rey, Villa del Rey, Boca La Caja y Paitilla [6].

\section{Teledetección}

La teledetección nos permite observar grandes regiones gracias a las longitudes de ondas, que son útiles para controlar y monitorear los recursos del planeta [7]. Por ello, es de vital importancia el uso de la teledetección en diversos estudios de asentamientos informales en Panamá, con el fin de ayudar al proceso de ordenamiento territorial, y aumentar el bienestar social, usando diversos programas técnicos que, combinado con métodos de campo como la topografía y la geodesia, optimizan y regulan dichos procesos.
Con la teledetección como levantamiento indirecto, obtenemos imágenes que pueden ser vistas de distintas alturas; esto se debe a las distintas maneras y diferentes plataformas, donde el área de la superficie escaneada por los sensores, cubrirá mayor parte si están mucho más alejados. En este sentido, existen tres niveles en que se clasifican las plataformas de teledetección [8]:

- Nivel I: Agrupa los instrumentos que operan desde el nivel del suelo hasta los aviones de gran altitud.

- Nivel II: Incluye los dispositivos ubicados en ingenios de órbita bajas (Trasbordador espacial, estación orbital) hasta los satélites de observación de órbitas polares hasta 1000 $\mathrm{km}$.

- Nivel III: Son los satélites de observación meteorológica situados en órbita geoestacionaria a casi $36.000 \mathrm{Km}$ de la Tierra.

\section{Casos de Estudio}

En el presente estudio se evaluaron tres asentamientos informales en la Provincia de Panamá.

El primero, la comunidad de Kuna Nega, con una población de 6000 habitantes, está ubicado en el Corregimiento de Ancón, detrás del relleno sanitario denominado como Cerro Patacón. La población de este asentamiento aumenta gradualmente, ya que cada vez se da la migración desde la Comarca Guna Yala, se construyen más viviendas precarias con pedazos de madera, planchas de zinc y otros materiales extraídos del vertedero. Su característica topográfica es irregular, con algunas pendientes altas que, con el pasar de los años los habitantes han mejorado para poder movilizarse a realizar algunas actividades para subsistir, ya que no cuentan con las mejores condiciones de vida [9].

El segundo, Altos de la Torre, ubicado en el corregimiento Arnulfo Arias, en el distrito de San Miguelito. Este asentamiento está compuesto por 463 familias que cuentan con viviendas hechas de madera, cartón comprimido y planchas de zinc; y no cuenta con los servicios básicos como luz, agua potable y alcantarillados [10].

El tercero, Paso Blanco, ubicado en el Corregimiento de las Garzas, distrito de Panamá, cuenta con una población de 9,579 habitantes. Posee una topografía mixta, que está siendo ocupada por la necesidad habitacional, que ha inducido a muchas familias a establecerse en esta área, lo que ha incrementado el número de la población en la misma [8].

\section{Metodología}

Se realizó el análisis de las vías de acceso de los asentamientos informales. Para ello se siguieron los siguientes pasos: 
- Se localizaron los asentamientos informales a través de Google Earth.

- Entramos a nuestra aplicación de Google Maps, para anotar los nombres de las calles, escuelas y entidades de atención médica más cercanas y otras comodidades próximas a los asentamientos.

- Se descargaron las imágenes satelitales a través del programa SAS Planet para los tres asentamientos informales. Dicho programa descarga imágenes Georreferenciadas en el formato TIFF y proporciona las distancias y visualizaciones de varios lugares.

- Se insertaron las imágenes al programa ArcMap de ArcGIS Desktop. Se cargaron las carpetas de las imágenes y se montó un base maps, con el fin de verificar su georreferenciación.

- Se creó un Geodatabase para cada uno de los asentamientos. Se crearon las feature class, y se programaron datos evaluados dentro los atributos, tales como calles, atención médica y escuelas próximas a los asentamientos. Las Feature Class para cada uno de los atributos son puntos, líneas y polígonos, según corresponda.

- Se digitalizaron cada uno de los sitios dándole inicio al Editor de la tabla de herramientas del programa.

- Para la digitalización de las calles se utilizaron las herramientas Straight Segment y Arc Segment, que se indican como trazados de líneas; las escuelas, atención médica y otras comodidades se indican en formato de puntos tal como se muestra en la figural.

- Para la clasificación no supervisada, se utilizó la herramienta de análisis Image Classification la cual muestra las imágenes a través de las bandas espectrales.

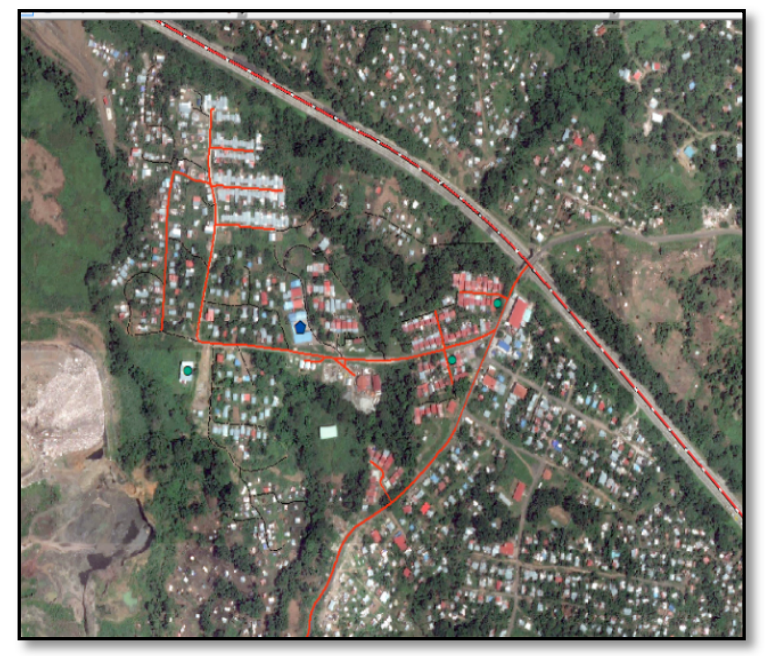

Figura 1. Resultado de nuestro asentamiento informal.

\section{Resultados}

Se analizaron y compararon la figura 2 y la figura 3, que muestra la digitalización de Kuna Nega y Paso blanco respetivamente, donde se observó que ambos tienen una topografía mixta. Además, el área de Paso Blanco tiene mayor cantidad de vías secundarias que son próximas a las vías principales; que es la que tiene prelación sobre las vías ordinarias, mediante la cual se pudo ver que cuenta con mayor movilidad hacia las escuelas, atención médica y otros sitios de interés [11].

Se pudo comprobar también que Altos de la Torre, no tiene vías de acceso secundarias, contiene una movilización más restringida con relación a los otros dos asentamientos. Los caminos están hechos de piedras y tierra, lo cual dificulta el acceso a este asentamiento.

Las características de habitabilidad son escasas en las áreas de Kuna Nega como se muestra en la figura 3, ya tienen muy pocas comodidades o sitios de interés. Altos de la Torre como se muestra en la figura 4, en comparación con Paso Blanco no tienen rutas de acceso adecuadas ya que está rodeado por el Corredor Norte. Dos de los asentamientos están cerca de Carreteras de alto flujo vehicular, uno cerca de la Autopista Panamá-Colón y el otro al Corredor Norte, esto desmejora la calidad de vida ya que tienen que lidiar con la Contaminación Acústic.

\section{Conclusiones}

Las imágenes digitalizadas sirven para mostrar el trazado de las vías de acceso hacia los asentamientos informales, que en muchos casos son senderos como consecuencia de la falta de calles secundarias para ingresar a los mismos. Para llegar a estos lugares durante temporada lluviosa es imposible, ya que los caminos se sedimentan provocando que los habitantes no puedan desplazarse de manera directa y más fácil. Las calles principales observadas en dos de los comparables son de alto riesgo, puesto que están hechas para autos y no para peatones.

A través del estudio y comparaciones hechas con los asentamientos informales se logró observar la carencia y dificultad con la que las personas tienen acceso a lugares básicos.

La movilidad hacia el asentamiento de Altos de la Torres y Paso Blanco en comparación con Kuna Nega no cuenta con un sistema de transporte regulado. 


\section{ASENTAMIENTO INFORMAL - PASO BLANCO}

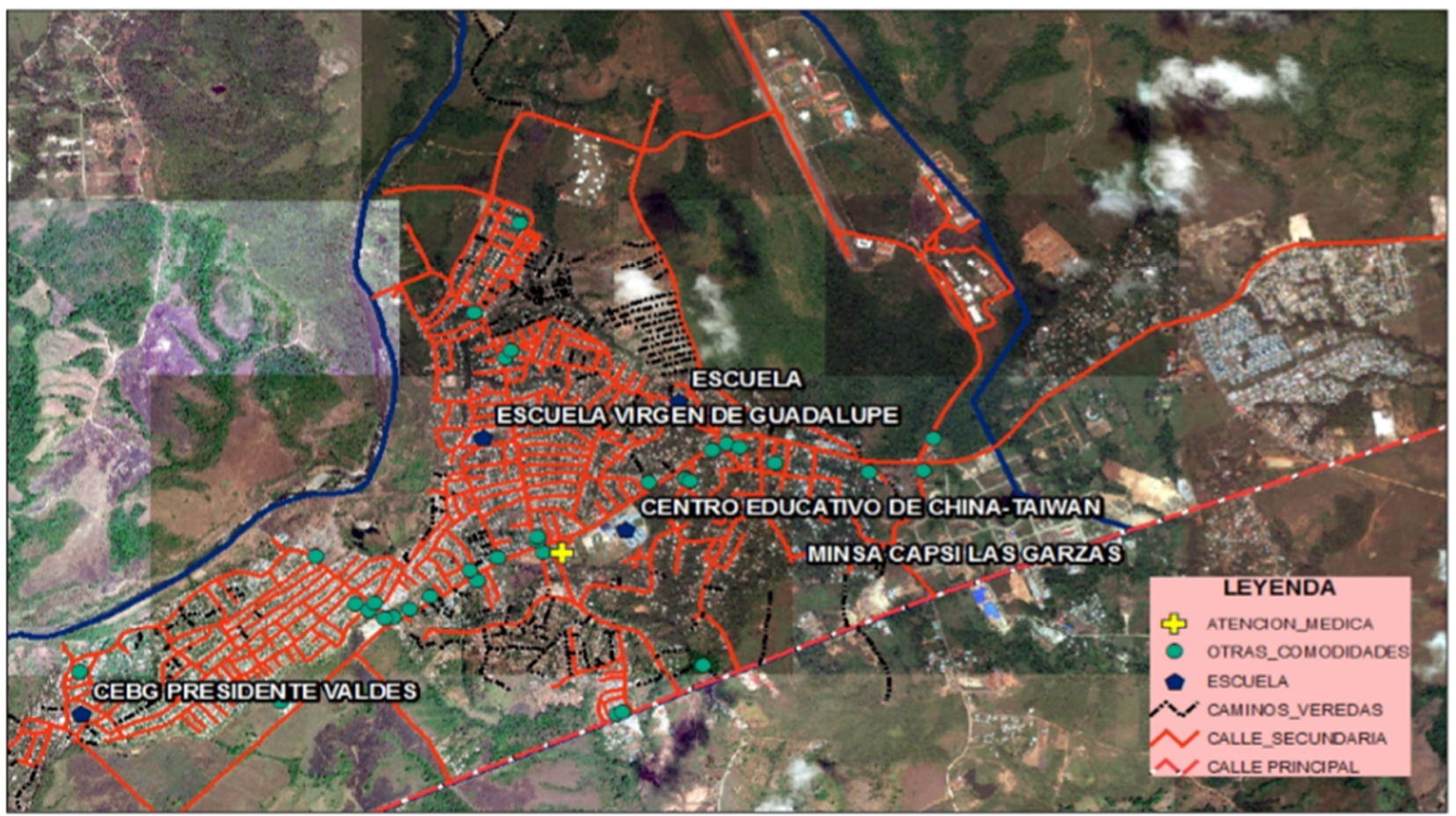

\section{CLASIFICACIÒN NO SUPERVISADA DE PASO BLANCO}

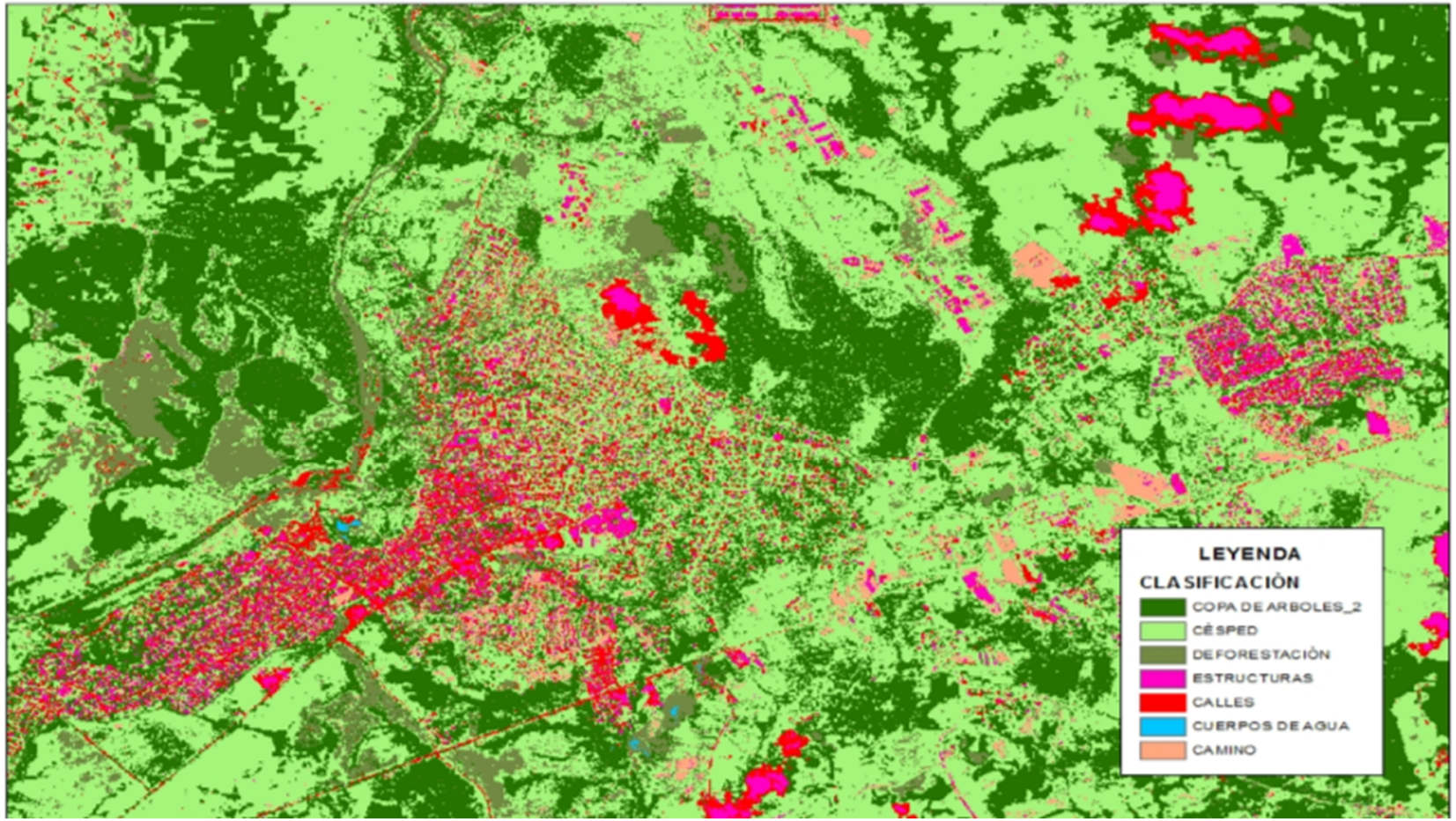

Figura 2. Digitalización y clasificación del Asentamiento Paso Blanco.

Fuente: Elaboración propia 
Manzané (et al): Aplicación de la teledetección para el análisis de vías de acceso hacia asentamientos informales

ASENTAMIENTO INFORMAL - KUNA NEGA

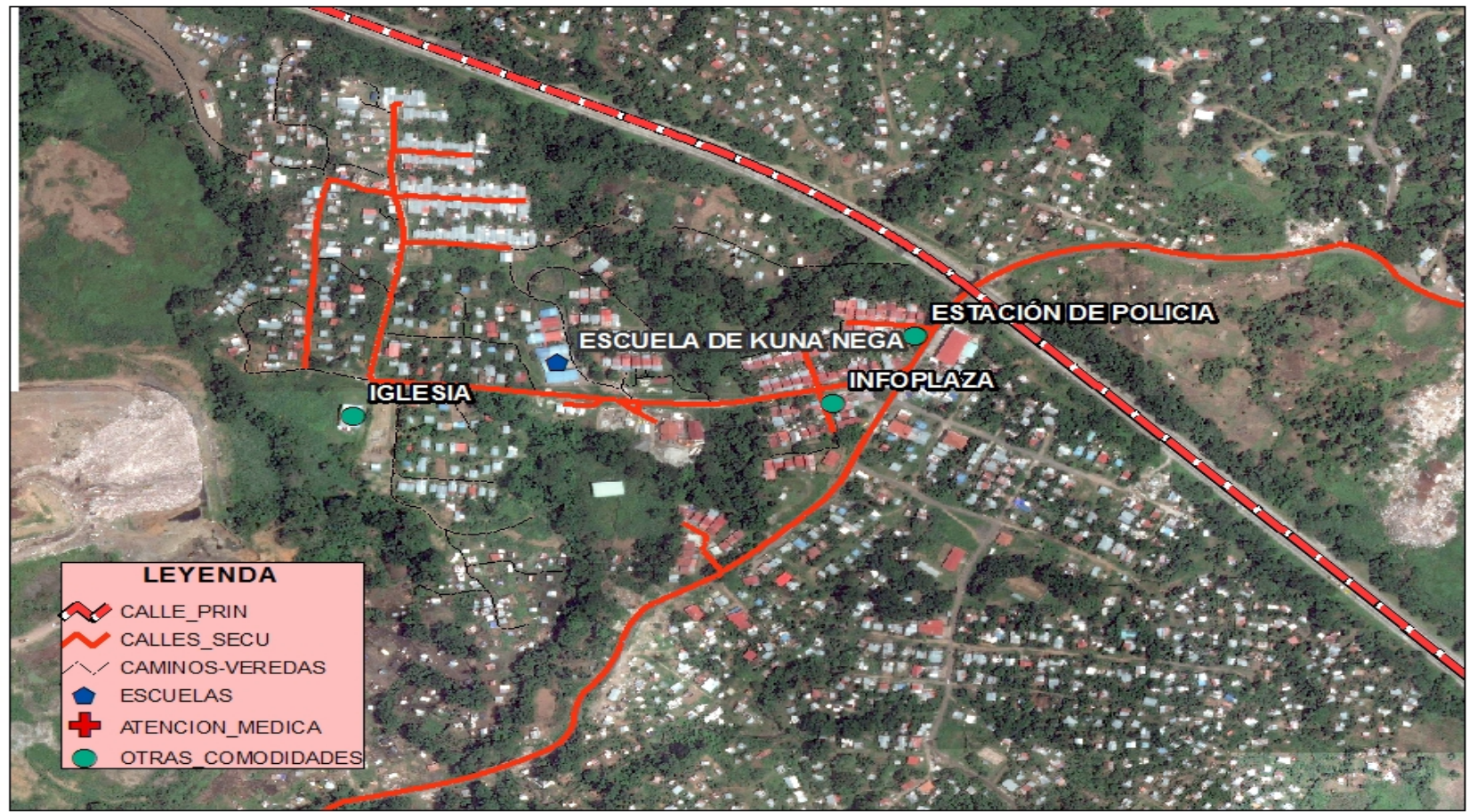

CLASIFICACIÒN NO SUPERVISADA DEL ASENTAMIENTO KUNA NEGA

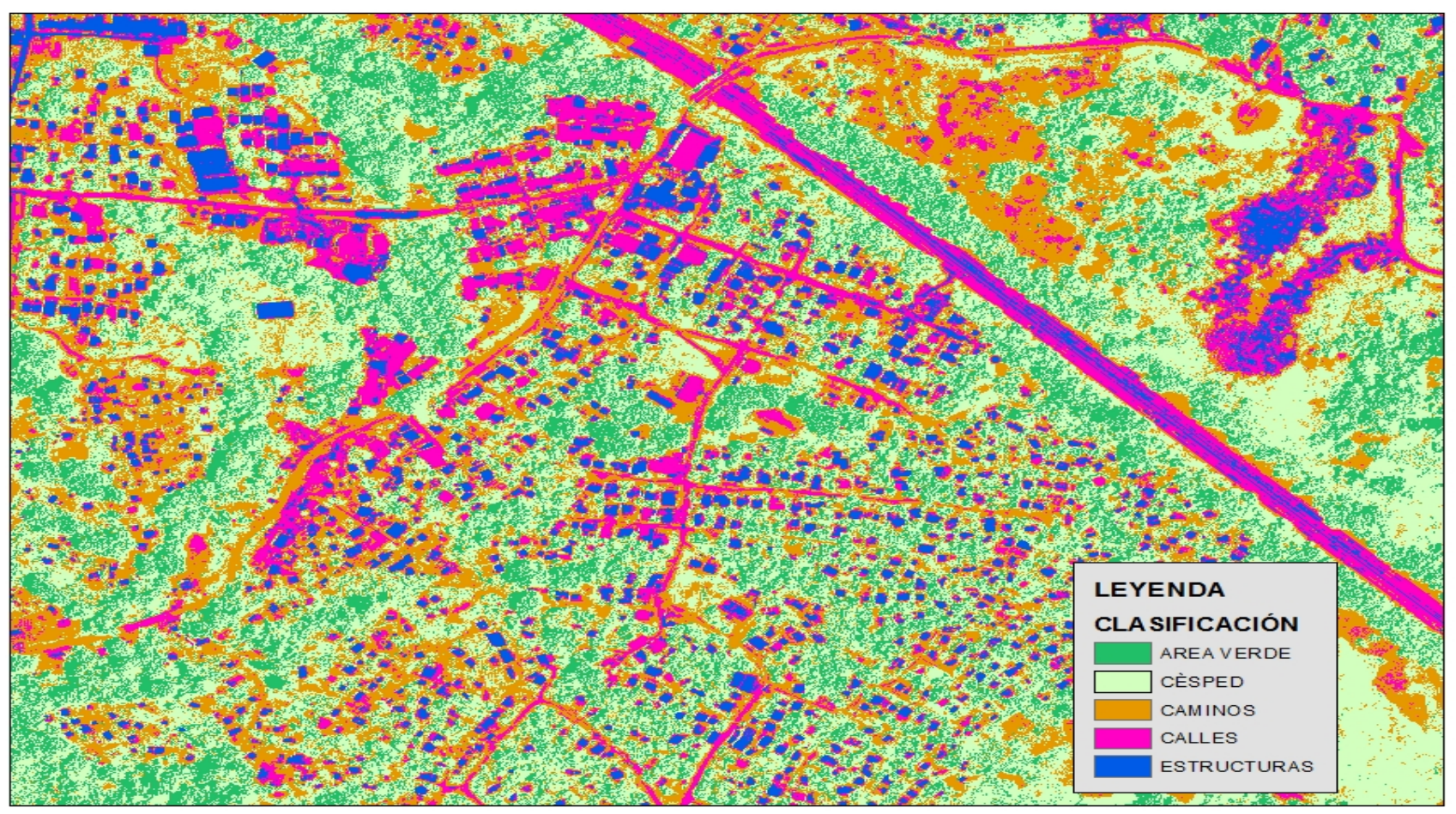

Figura 3. Digitalización del Asentamiento Kuna Nega.

Fuente: Elaboración propia. 
Manzané (et al): Aplicación de la teledetección para el análisis de vías de acceso hacia asentamientos informales
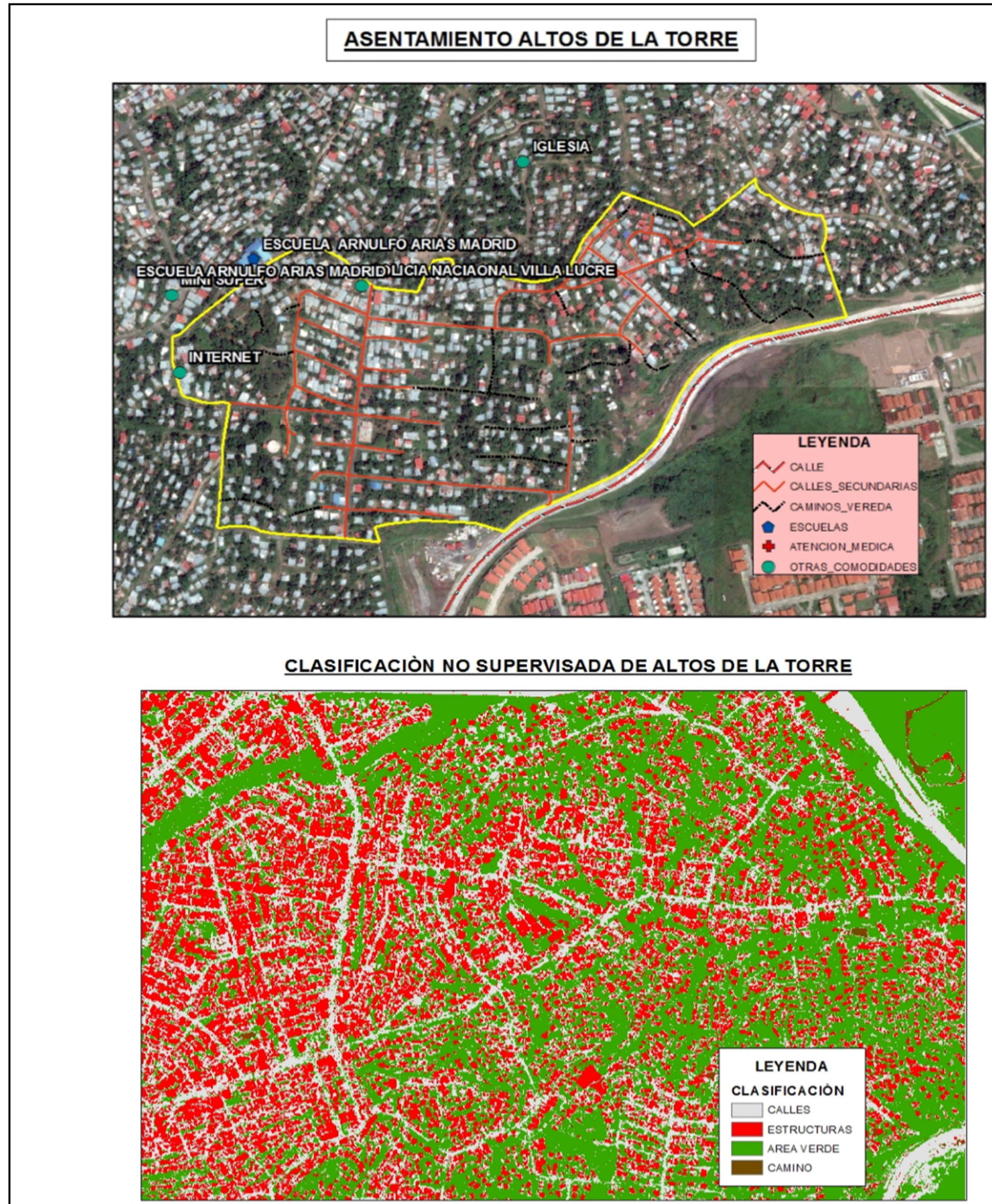

Figura 4. Digitalización de Altos de la Torre.

Fuente: Elaboración propia. 
El asentamiento de Altos de la Torre es el más pequeño en comparación con los otros dos casos de estudio, y sus habitantes enfrentan mayores dificultades para movilizarse, ya que colinda con el Corredor Norte que es una vía primaria de alto impacto debido a la alta velocidad que van los autos, y sus calles secundarias se encuentran a mayor distancia.

Es necesario plantear planes de ordenamiento territorial para regularizar los asentamientos informales, para los cuales es de suma importancia las imágenes satelitales y la teledetección que nos permitirá caracterizar los mismos. Este plan de ordenamiento territorial se deberá desarrollar después de la titulación de tierras, para adecuar una planificación del transporte en conjunto.

Esta investigación es de suma importancia para las comunidades que necesitan mejorar su calidad de vida, ya que es una herramienta potencial para la toma de decisiones.

\section{REFERENCIAS}

[1] GTZ. CEPAL. "Legislación Modelo de Conservación Vial", Comisión Económica para América Latina y el Caribe, Santiago de Chile 1995, pp. 57.

[2] M. Arvelo. (2006). Introducción a la Teledetección. Universidad de la Laguna, pp 1-3. Available: http://concurso.cnice.mec.es/cnice2006/material121/unidad1/def in_td.htm.

[3] MIVIOT. (2015). "Uso de sus Facultades Legales", (Nov, 2015), pp 1, [Online]. Available: https://dpu.mupa.gob.pa/wpcontent/uploads/2017/06/RES-732-2015-REQUISITOSESQUEMAS-EOT.pdf [Ultimo acceso abril 2018].

[4] E. Fernández (2012, mayo). "Definición de los Asentamientos Irregulares.” María. [Online]. pp.1. Available:http://www.mariaonline.com/travel/article.php?lg=es\&q=Asentamiento_irregular [último acceso abril 2018].

[5] D Hernández. D. Sánchez. (2013). "Qué es Movilidad Urbana”, Banco de Desarrollo de América Latina, (agosto 2013) [Online]. Available:

https://www.caf.com/es/actualidad/noticias/2013/08/que-esmovilidad-urbana/?parent=14062 [Ultimo acceso abril 2018]

[6] Pizzurno. (2016 Nov). "Evolución histórica de la ciudad de panamá: la construcción del paisaje urbano histórico y la identificación de los riesgos durante su evolución". [Online]. Available: http://www.metromapas.net/2016/11/17/283/[ultimo acceso abril 2018]

[7] Ocwuniversia. "Historia de la Teledetección." Tecnología del medio Ambiente [Online], pp.2-50. Available: http://ocw.innova.uned.es/ocwuniversia/tecnologias-del-medioambiente/curso-basico-de-teledeteccion/curso/material/historiade-la-teledeteccion.pdf[ultimo acceso abril 2018]

[8] Contraloría General de la República de Panamá, Instituto Nacional de Estadística de Censo. "Censo del 2010”. (2012, enero). Pp 1362-1364. Available: https://www.contraloria.gob.pa/inec/Publicaciones/Publicaciones .aspx?ID_SUBCATEGORIA=59\&ID_PUBLICACION=362\&I D_IDIOMA=1\&ID_CATEGORIA=13. [Ultimo acceso abril 2018].

[9] Ministerio de Salud Panamá. "Construcción del Nuevo Centro de Salud de Kuna Nega." [Online], pp 3-8. Available:
(http://siproy.mef.gob.pa/tab/21795_2014_9072_Perfil\%20-\%20 KUNA\%20NEGA.docx[Ultimo acceso abril 2018].

[10] Alcaldía de San Miguelito. (2018, Mar). "Plan Estratégico." [Online], pp.73. Available: http://alcaldiadesanmiguelito.org/wpcontent/uploads/2018/03/9.3-Plan-Estrat\%C3\%A9gico-SM.pdf. [Ultimo acceso 2018].

[11] Redacción el Tiempo. (1995). "las vías tienen su significado conózcalo y evite multas". Archivo [Online]. Available: http://www.eltiempo.com/archivo/documento/MAM-499323 [Ultimo acceso abril 2018].

\section{I4 1 RIC}

